\title{
Avaliação clínica de bochechos com extratos de Aroeira (Schinus terebinthifolius) e Camomila (Matricaria recutita L.) sobre a placa bacteriana e a gengivite
}

\author{
LINS, R..'; VASCONCELOS, F.H.P.'; LEITE, R.B.. ${ }^{1 *}$; COELHO-SOARES, R.S. ${ }^{1}$; BARBOSA, D.N. ${ }^{1}$ \\ ${ }^{1}$ Universidade Estadual da Paraíba (UEPB), Rua Baraúnas, 351 - Bairro Universitário - Campina Grande-PB, \\ CEP 58429-500, Brasil. *rrafaella_bastos@hotmail.com
}

\begin{abstract}
RESUMO: A presente pesquisa objetivou avaliar clinicamente o efeito de bochechos à base de extratos das plantas medicinais, aroeira (Schinus terebinthifolius) e camomila (Matricaria recutita L.), sobre o controle da placa bacteriana e o tratamento da gengivite. Para tanto, foi realizado um ensaio clínico randomizado, duplo cego, intervencionista, envolvendo 59 indivíduos adultos atendidos na Clínica do Curso de Odontologia da Universidade Estadual da Paraíba (UEPB). A amostra foi constituída por pacientes portadores de gengivite crônica. A referida amostra foi selecionada aleatoriamente e dividida em três grupos: bochecho com Clorexidina (grupo controle positivo); bochecho com Camomila (grupo teste 1); bochecho com Aroeira (grupo teste 2). Durante a primeira visita do paciente, e, previamente à realização dos bochechos, todos foram orientados quanto à higiene bucal e submetidos ao procedimento de raspagem e alisamento radicular (RAR) da boca toda em uma única sessão. Os bochechos foram realizados a partir do primeiro atendimento clínico até o $15^{\circ}$ dia após o início do tratamento, na frequência de duas vezes ao dia. Para avaliação da condição periodontal da amostra realizada no $1^{\circ}, 7^{\circ} \mathrm{e} 15^{\circ}$ dias foram aplicados os Índices de Sangramento Gengival (ISG) e de Placa (IP). Os pacientes foram reavaliados 7 e 15 dias após o início do uso do respectivo bochecho. Os resultados apontaram que o IP e o ISG apresentaram redução significativa nos três grupos. Quanto ao IP, o bochecho de camomila obteve a maior redução de acúmulo de placa e o bochecho de aroeira, a menor redução. Para os índices de sangramento, os resultados foram equivalentes, de forma que não foram consideradas diferenças estatisticamente significativas entre os bochechos. Foram considerados satisfatórios os bochechos a base de Camomila (Matricaria recutita L.) e Aroeira (Schinus terebinthifolius) na redução do quadro de inflamação gengival da amostra, sendo o bochecho de Camomila (Matricaria recutita L.) o que apresentou melhor desempenho na redução do índice de placa bacteriana.
\end{abstract}

Palavras-chave: Periodontia, Fitoterapia, Gengivite.

ABSTRACT. Clinical evaluation of mouthwash with extracts from aroeira (Schinus terebinthifolius) and chamomile (Matricaria recutita L.) on plaque and gingivitis. This study aimed to clinically evaluate the effect of mouthwash with extracts from the medicinal plants aroeira (Schinus terebinthifolius) and chamomile (Matricaria recutita L.) on plaque control and gingivitis treatment. Thus, a randomized, double-blind interventional clinical trial was conducted, involving 59 adults treated at the Clinics of the Dentistry Program of Univ Estadual da Paraíba (UEPB). The sample consisted of patients with chronic gingivitis. This sample was randomly selected and divided into three groups: mouthwash with chlorhexidine (positive control group), mouthwash with chamomile (test group 1); mouthwash with aroeira (test group 2). During the first visit, and prior to rinses, all patients were instructed in oral hygiene and subjected to scaling and root planing procedure (SRP) of the whole mouth in one single session. Rinses occurred from the first clinical appointment to the $15^{\text {th }}$ day after the beginning of treatment, twice a day. To evaluate the periodontal condition of the sample on the $1^{\text {st }}, 7^{\text {th }}$ and $15^{\text {th }}$ days, Gingival Bleeding Index $(\mathrm{GBI})$ and Plaque Index $(\mathrm{PI})$ were used. The patients were reassessed at 7 and 15 days after the beginning of the respective rinses. Results indicated that $\mathrm{PI}$ and GBI significantly decreased in all three groups. As to PI, chamomile mouthwash led to the greatest reduction in plaque buildup, while aroeira mouthwash resulted in the smallest reduction. For bleeding rates, results were equivalent so that statistical differences among rinses were not

Recebido para publicação em 04/08/2011

Aceito para publicação em 08/08/2012

Rev. Bras. PI. Med., Botucatu, v.15, n.1, p.112-120, 2013. 
considered significant. Mouthwashes with chamomile (Matricaria recutita L.) and aroeira (Schinus terebinthifolius) were considered satisfactory in reducing gingival inflammation in the sample; in addition, mouthwash with chamomile (Matricaria recutita L.) showed the best performance in reducing the plaque index.

Key words: Periodontics, phytotherapy, gingivitis

\section{INTRODUÇÃO}

O biofilme dental é o fator de maior importância na etiologia da cárie e das doenças periodontais e há uma relação muito grande com a higiene bucal deficiente (Pereira, 1999; DomejeanOrliaguet et al., 2006; Gutmann et al. 2009; Beikler \& Flemmig, 2011). A remoção mecânica constitui o método mais aceito para o seu controle, mas o uso de coadjuvantes químicos é bastante valioso (Jardim Júnior et al., 1998).

A placa bacteriana pode ser visível na superfície dentária após um ou dois dias se os procedimentos de higiene bucal forem insatisfatórios. A localização e quantidade de sua formação são variadas, dependendo de fatores determinantes, tais como a dieta e o fluxo salivar. Depois de 10 a 21 dias de acúmulo de placa bacteriana supragengival, sinais clínicos da gengivite aparecem, tais como vermelhidão, edema e uma tendência ao sangramento marginal à uma suave sondagem (Van der Weijden et al., 1994; Tatakis \& Kumar, 2005; Kinane \& Barthold, 2007)

A gengivite é uma das doenças periodontais mais freqüentes, afetando mais de $90 \%$ da população, independentemente da idade, sexo ou raça (Villaloboset al., 2001). Estudos epidemiológicos brasileiros demonstraram uma alta prevalência de inflamação gengival, variando de $74 \%$ a $100 \%$, embora a média individual de sangramento gengival varie de $28 \%$ para $35 \%$ (Salgado et al., 2006).

Múltiplas modalidades terapêuticas foram testadas e utilizadas no decorrer do tempo com a finalidade de combater, inibir, ou reduzir a microbiota patogênica bucal, sem uma efetividade para garantir a sua indicação para a população em geral. Particularmente, bons resultados foram encontrados com o uso da clorexidina, o mais eficiente agente químico na redução da placa bacteriana e da gengivite (Gjermo et al., 2000).

A clorexidina está bem caracterizada como um excelente agente antiplaca utilizado no tratamento e na prevenção da gengivite, sendo também usada como referência em estudos de teste de eficiência de outros agentes antimicrobianos (Gunsolley, 2006). A clorexidina tem mínimos efeitos tóxicos (os valores mínimos de toxicidade oral e intravenosa são, respectivamente, 1.800 e $22 \mathrm{mg} / \mathrm{kg}$ ), e não foi reportado nenhum efeito teratogênico ou carcinogênico (Petti \& Hausen,
2006). Contudo, alguns efeitos colaterais têm sido relatados, incluindo a pigmentação extrínseca nos dentes, em restaurações e no dorso da língua, descamação da mucosa e sensibilidade oral, além de reações alérgicas. O gosto amargo da solução e a interferência na sensação gustativa ocorre por algumas horas após o bochecho (Loureiro et al., 2004).

O uso de plantas com finalidade terapêutica tem ampla aceitação popular e apoio da Organização Mundial de Saúde, motivando pesquisas científicas (Santos \& Amorim, 2002). Esse tipo de terapia alternativa vem sendo procurada para o combate a doenças com baixo custo e fácil acesso (Werkman et al., 2008).

Oliveira et al. (2007), ao pesquisarem os principais estudos relacionados à plantas medicinais utilizadas em patologias da cavidade oral, encontraram relato do uso de 132 espécies de plantas, sendo a romã (Punica granatum L.) a mais citada para o uso odontológico.

A Organização Mundial de Saúde (OMS, 2006) estima que $80 \%$ da população do planeta, de algum modo, utiliza plantas medicinais como medicamentos. Estima-se também, que 25 mil espécies de plantas sejam usadas nas preparações da medicina tradicional (Guerra et al., 2000).

Um dos fatores que contribui para a larga utilização de plantas para fins medicinais no Brasil é o grande número de espécies vegetais encontradas no país. Nos últimos anos, tem aumentado a aceitação da fitoterapia no Brasil, resultando em crescimento da produção industrial dos laboratórios. Observa-se também o surgimento de cultivos caseiros e de novos usuários, havendo necessidade de orientação à população (Borba \& Macedo, 2006).

Para Lima Jr. \& Dimenstein (2006), o programa de Plantas Medicinais e Fitoterápicos da Política Nacional de Práticas Integrativas e Complementares do SUS visa estimular profissionais da área de saúde bucal a adotar plantas medicinais em seu esquema terapêutico, bem como orientar a população acerca do uso destas substâncias, conhecendo seus efeitos, contra-indicações e riscos. O emprego de fitoterápicos só tem a contribuir para a saúde de quem o pratica, quando feito com critérios, incluindo a identificação do quadro clínico (doença ou sintoma), a escolha correta da planta a

Rev. Bras. PI. Med., Botucatu, v.15, n.1, p.112-120, 2013. 
ser utilizada, e a sua adequada preparação.

Enquanto o conhecimento popular tem consagrado a camomila (Matricaria recutita L.) como um eficaz antiinflamatório, a literatura científica vem confirmando esse conhecimento até então empírico e instintivo. A camomila (Matricaria recutita L.) pertence à família das Asteraceae (compostas) e recebe outras sinonímias como: camomilacomum, camomila vulgar, camomila legítima, camomila dos alemães, matricária e macela. A $M$. recutita é uma das poucas plantas medicinais cujos constituintes químicos foram exaustivamente avaliados farmacologicamente, inclusive em testes clínicos. A atividade antiinflamatória da droga deve-se à presença de óleos essenciais, ricos em azuleno, matricina e alfa-(-)-bisabolol. (AchterrahtTuckermann et al., 1980; Ammon \& Kaul, 1992; Braga et al., 2009; Srivastava et al., 2009)

A aroeira (Schinus sp.) possui ação antimicrobiana, anti-inflamatória e antiulcerogênica, sendo utilizada como antisséptico e no tratamento de estomatites. Além disso, apresenta atividade bactericida e bacteriostática sobre Streptococus mutans, Streptococus mitis, Streptococus sobrinus, Streptococus sanguis, (Lactobacillus casei) e ação antifúngica sobre Cândida albicans, Cândida tropicalis e Cândida krusei (Brandão et al., 2007).

Frente ao exposto, o presente trabalho se propôs a avaliar clinicamente o efeito de bochechos à base de clorexidina e de extratos das plantas medicinais, aroeira (Schinus terebinthifolius) e camomila (Matricaria recutita L.), sobre a placa bacteriana e a gengivite, comparando os resultados obtidos entre os grupos estudados e a sua possível utilização como método auxiliar na prevenção das doenças periodontais.

\section{MATERIAIS E MÉTODOS}

Foi realizado um estudo clínico comparativo, do tipo ensaio clínico randomizado controlado, duplo cego, intervencionista, experimental, longitudinal e prospectivo, com uma abordagem indutiva, envolvendo 59 pacientes com idades entre 18 e 83 anos atendidos nas Clínicas Integradas do Departamento de Odontologia da Universidade Estadual da Paraíba (UEPB) que, após o exame clínico, foram diagnosticados como portadores de gengivite crônica, tendo após o diagnóstico, lido e assinado o Termo de Consentimento Livre e Esclarecido. Seguindo os preceitos da Resolução CNS/MS 196/96, este projeto foi registrado no SISNEP (CAAE 0076.0.133.000-10) e aprovado pelo Comitê de Ética em Pesquisa da Universidade Estadual da Paraíba e posterior envio para o CONEP.

Os critérios de inclusão foram: indivíduos de ambos os sexos, com idade igual ou superior a 18 anos, de cor branca ou não branca, portadores de gengivite crônica, sistemicamente saudáveis e sem história médica ou medicamentosa recente. Enquanto os critérios de exclusão foram: Indivíduos com periodonto sadio ou condição periodontal sugestiva de periodontite, portadores de doenças ou condições sistêmicas com repercussão periodontal, doenças sistêmicas que necessitam de profilaxia antibiótica para a realização da terapia periodontal, bem como portadores de Diabetes Mellitus, indivíduos imunocomprometidos, gestantes, lactantes e usuários de drogas com repercussão periodontal, além daqueles submetidos à antibioticoterapia nos últimos três meses.

A amostra foi dividida aleatoriamente, através de um sorteio (utilizando números seqüenciais mantidos em envelopes opacos, não translúcidos e fechados), em dois grupos de 20 pacientes cada um e um grupo de 19 pacientes, de acordo com o tipo de tratamento: Grupo $1\left(G_{1}\right)-$ Bochecho com Clorexidina (grupo controle positivo); Grupo $2\left(\mathrm{G}_{2}\right)$ - Bochecho com Camomila (grupo teste 1); Grupo $3\left(G_{3}\right)$ - Bochecho com Aroeira (grupo teste 2).

As amostras de aroeira rasurada (Schinus terebinthifolius) e de camomila flor (Matricaria recutita $L$.) foram adquiridas em loja comercial de ervas situada na cidade de São Paulo, SP, sob registro no Conselho Regional de Farmácia $n^{\circ}$ 20505. As plantas foram identificadas através de laudo técnico disponibilizado pelo fornecedor. Os extratos hidroalcóolicos de aroeira e da camomila foi preparados seguindo as recomendações da Farmacopéia Brasileira $4^{a}$ ed. (1988-1996).

Os pacientes foram avaliados, utilizandose o Índice de Placa e o Índice de Sangramento Gengival, em três oportunidades: a) no primeiro dia de pesquisa, previamente ao início do uso do respectivo bochecho; b) no $7^{\circ}$ dia após o início do tratamento com o bochecho; e c) no $15^{\circ}$ dia após o início do tratamento com o bochecho. No primeiro dia, todos os pacientes dos três grupos foram submetidos aos seguintes procedimentos: Orientação de Higiene Bucal (OHB); Raspagem e Alisamento Radicular (RAR) da boca toda em uma única sessão, utilizando apenas instrumentos manuais, especialmente as curetas de McCall 1314 e 17-18, para dentes anteriores e posteriores, respectivamente; profilaxia com pedra pomes e pasta profilática; e, por fim, o bochecho com a substância referente ao grupo a que o paciente pertencia.

O Índice de Placa (Silness \& Löe, 1964) possibilita a avaliação da presença e do nível de placa bacteriana nas quatro superfícies dentárias (vestibular, lingual ou palatina, mesial e distal) dos

Rev. Bras. PI. Med., Botucatu, v.15, n.1, p.112-120, 2013. 
elementos $16,12,24,36,32$ e 44 , os quais recebem escores que variam de 0 a 3. Por sua vez, o Índice de Sangramento Gengival à Sondagem (ISG) (Ainamo \& Bay, 1975) corresponde à investigação de sangramento com base na dicotomia "sangra/ não sangra" à sondagem após dez segundos da mensuração. Os valores percentuais do ISG são agrupados nos seguintes escores: sem sangramento (1); de 1 a $10 \%$ de faces com sangramento (2); de 11 a $25 \%$ (3); de 26 a $50 \%$ (4); de 51 a $75 \%$ (5); acima de $75 \%$ de faces com sangramento (6). Considerase com inflamação gengival leve os pacientes enquadrados no escore 2, inflamação gengival moderada aqueles com escore 3 e severa, aqueles com escores superiores a 3 .

Os pacientes foram orientados a realizar dois bochechos diários com a solução correspondente ao seu grupo, diluída em $1 / 2$ copo $(250 \mathrm{ml})$ de água, 30 minutos após as escovações dentárias matutina e noturna, com um minuto de duração, e por um período determinado de 15 dias.

Os dados foram consolidados no programa SPSS (Statistical Package for Social Sciences), versão 18.0, e analisados por meio de estatística descritiva e inferencial uni e bivariada. Para os procedimentos descritivos foram apresentadas medidas de tendência central (média) e dispersão (desvio-padrão). Os procedimentos de inferência estatística foram feitos com base em estatística nãoparamétrica, por meio de uma Análise de Variância (ANOVA) para amostras independentes (teste de Kruskal-Wallis) e medidas repetidas (teste de Friedman). Foram realizadas ainda, comparações emparelhadas por meio dos testes $U$ de MannWhitney e Wilcoxon. A significância utilizada foi de 0,05 com $95 \%$ de intervalo de confiança.

\section{RESULTADOS}

Obteve-se uma amostra com faixa etária de 18 a 83 anos e média de idade de 34 anos, composta por maioria feminina $(64,4 \%)$, cor branca $(67,8 \%)$. Em relação à renda familiar, em salários mínimos
(SM), encontrou-se que: $49,1 \%$ apresentavam renda familiar de 1 a 2 SM; 33,9\% apresentavam renda de 3 a 4 SM; $3,4 \%$ de 5 a 6 SM; e 1,6\% apresentavam renda familiar acima de 6 SM. Apenas $5(8,47 \%)$ participantes relataram ser fumantes.

Quanto aos hábitos de higiene bucal, questionou-se a utilização do fio dental, de enxaguatório bucal, relato de uso de fitoterápico e realização de tratamento periodontal até 06 meses anterior à pesquisa, além do número de escovações diárias (Figura 1). Em relação ao uso de fio dental, a maioria, $35(59,3 \%)$ relatou não fazer uso. Em relação à utilização de enxaguatório bucal, 50 $(84,7 \%)$ dos pesquisados afirmaram não utilizá-lo. Quando questionados se já haviam utilizado alguma solução fitoterápica, apenas $1(1,7 \%)$ participante respondeu positivamente Mais da metade dos participantes $33(56 \%)$ relataram já terem sido submetidos a algum tratamento periodontal. $\mathrm{Na}$ tabela 1 verifica-se a distribuição destas variáveis pelos 3 grupos.

Quando pesquisados quanto ao número de escovações diárias, nenhum participante alegou escovar os dentes apenas 1 vez por dia, 22 (37,3\%) afirmaram escovar seus dentes por pelo menos 2 vezes por dia, $28(47,5 \%)$ disseram escovar os dentes 3 vezes por dia e apenas $9(15,2 \%)$ participantes afirmaram escovar 4 ou mais vezes os dentes por dia (Figura 1).

A avaliação da redução do índice de placa ao longo dos três momentos (inicial, após 7 e 15 dias), nos 3 grupos (Clorexidina, Camomila e Aroeira) foi realizada separadamente através do teste de Friedman. Os resultados apontaram que os índices de placa apresentaram uma redução significativa nos três grupos distintos. Ao se compararem os resultados destes índices entre os grupos nos momentos inicial, após 7 dias e após 15 dias, os resultados apontaram diferenças significativas apenas no momento inicial, apresentando o grupo do bochecho de aroeira os menores índices (teste de Kruskal-Wallis). Após 7 ou 15 dias, os resultados apresentaram pouca variabilidade, isto é, não houve

TABELA 1. Distribuição dos hábitos de higiene bucal (usos de Fio dental, de Enxaguatório e de Fitoterápico), presença de sangramento gengival e realização de tratamento periodontal anterior por bochecho estudado.

\begin{tabular}{|c|c|c|c|c|c|c|}
\hline & \multicolumn{2}{|c|}{ Clorexidina } & \multicolumn{2}{|c|}{ Camomila } & \multicolumn{2}{|r|}{ Aroeira } \\
\hline & Sim & Não & Sim & Não & Sim & Não \\
\hline Uso de Fio Dental & $8(40 \%)$ & $12(60 \%)$ & $7(35 \%)$ & $13(65 \%)$ & $9(47 \%)$ & $10(53 \%)$ \\
\hline Uso de Enxaguatório & $2(10 \%)$ & $18(90 \%)$ & $3(15 \%)$ & $17(85 \%)$ & $4(21 \%)$ & $15(79 \%)$ \\
\hline Uso de Fitoterápico prévio à pesquisa & $0(0 \%)$ & $20(100 \%)$ & $1(5 \%)$ & $15(95 \%)$ & $0(0 \%)$ & $20(100 \%)$ \\
\hline Presença de sangramento gengival & $18(90 \%)$ & $2(10 \%)$ & $17(85 \%)$ & $3(15 \%)$ & $12(63 \%)$ & $7(37 \%)$ \\
\hline Tratamento periodontal anterior & $9(45 \%)$ & $11(55 \%)$ & $15(75 \%)$ & $5(25 \%)$ & $9(47 \%)$ & $10(53 \%)$ \\
\hline
\end{tabular}

Rev. Bras. PI. Med., Botucatu, v.15, n.1, p.112-120, 2013. 


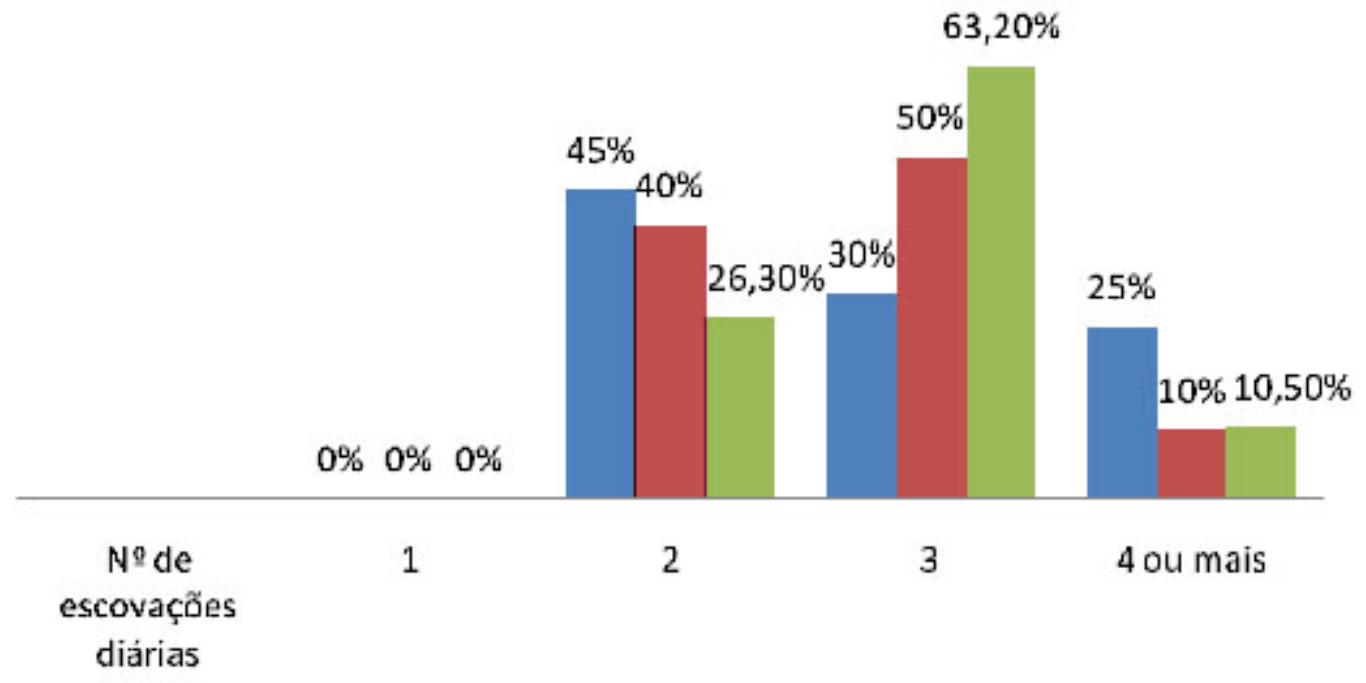

Clorexidina $=$ Camomila $=$ Aroeira

FIGURA 1. Percentual do número de escovações diárias para cada bochecho.

TABELA 2. Estatísticas descritivas e inferenciais dos índices de placa inicial, após 7 e 15 dias nos grupos Clorexidina, Camomila e Aroeira

\begin{tabular}{ccccc}
\hline Índices de Placa & Clorexidina & Camomila & Aroeira & Teste KW (p) \\
\hline Inicial & $1,23 \pm 0,31^{\text {a }}$ & $1,34 \pm 0,32 \mathrm{~b}$ & $0,99 \pm 0,28 \mathrm{ab}$ & $\mathbf{1 2 , 9 7 3 ( \mathbf { 0 , 0 0 2 } ) ^ { * }}$ \\
$\mathbf{7}$ dias & $0,67 \pm 0,29$ & $0,69 \pm 0,28$ & $0,58 \pm 0,22$ & $1,010(0,604)$ \\
$\mathbf{1 5}$ dias & $0,26 \pm 0,10$ & $0,30 \pm 0,15$ & $0,28 \pm 0,15$ & $0,610(0,737)$ \\
Teste de Friedman $(\mathbf{p})$ & $40,000(<0,001)$ & $40,000(<0,001)$ & $38,000(<0,001)$ & \\
\hline
\end{tabular}

KW: utilizando-se o teste de Kruskal-Wallis

*, a, b: diferenças estatisticamente significativas ao nível de 5\%.

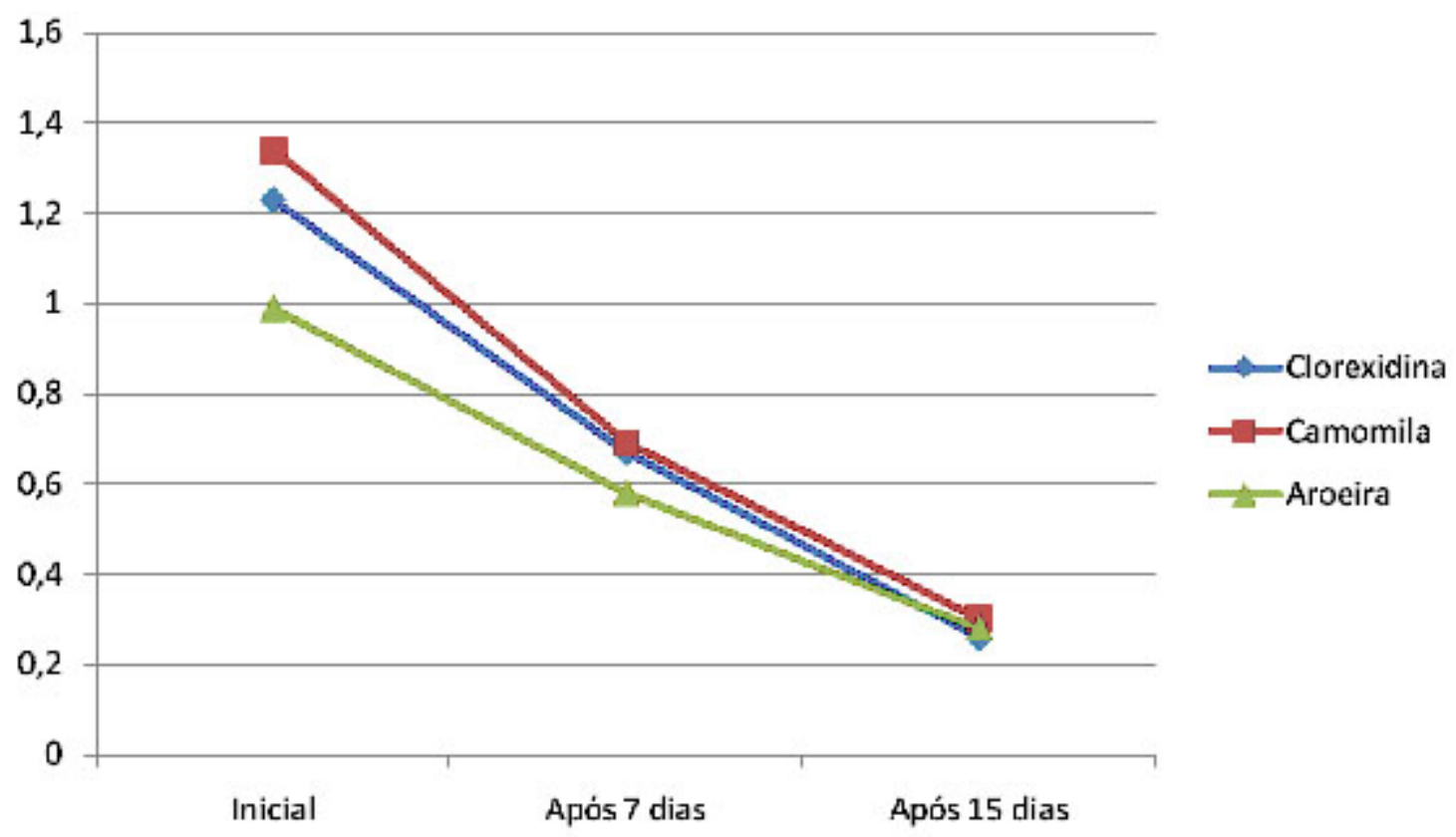

FIGURA 2. Índices de placa inicial, após 7 e 15 dias nos grupos Clorexidina, Camomila e Aroeira. 
TABELA 3. Estatísticas descritivas e inferenciais dos índices de sangramento inicial, após 7 e 15 dias nos grupos Clorexidina, Camomila e Aroeira

\begin{tabular}{ccccc}
\hline Índ. de Sang. & Clorexidina & Camomila & Aroeira & KW (p) \\
\hline Inicial & $0,49 \pm 0,09$ & $0,44 \pm 0,11$ & $0,41 \pm 0,14$ & $5,516(0,063)$ \\
$\mathbf{7}$ dias & $0,31 \pm 0,09 c$ & $0,27 \pm 0,08$ & $0,23 \pm 0,07 \mathrm{c}$ & $\mathbf{7 , 2 5 5}(\mathbf{0 , 0 2 7})^{*}$ \\
$\mathbf{1 5}$ dias & $0,18 \pm 0,06 \mathrm{~d}$ & $0,18 \pm 0,06$ & $0,15 \pm 0,07 \mathrm{~d}$ & $\mathbf{6 , 8 2 2}(\mathbf{0 , 0 3 3})^{*}$ \\
Teste de Friedman $(\mathbf{p})$ & $39,077(<0,001)$ & $39,519(<0,001)$ & $38,000(<0,001)$ & \\
\hline
\end{tabular}

$\mathrm{KW}$ : utilizando-se o teste de Kruskal-Wallis

*: diferenças estatisticamente significativas ao nível de $5 \%$.

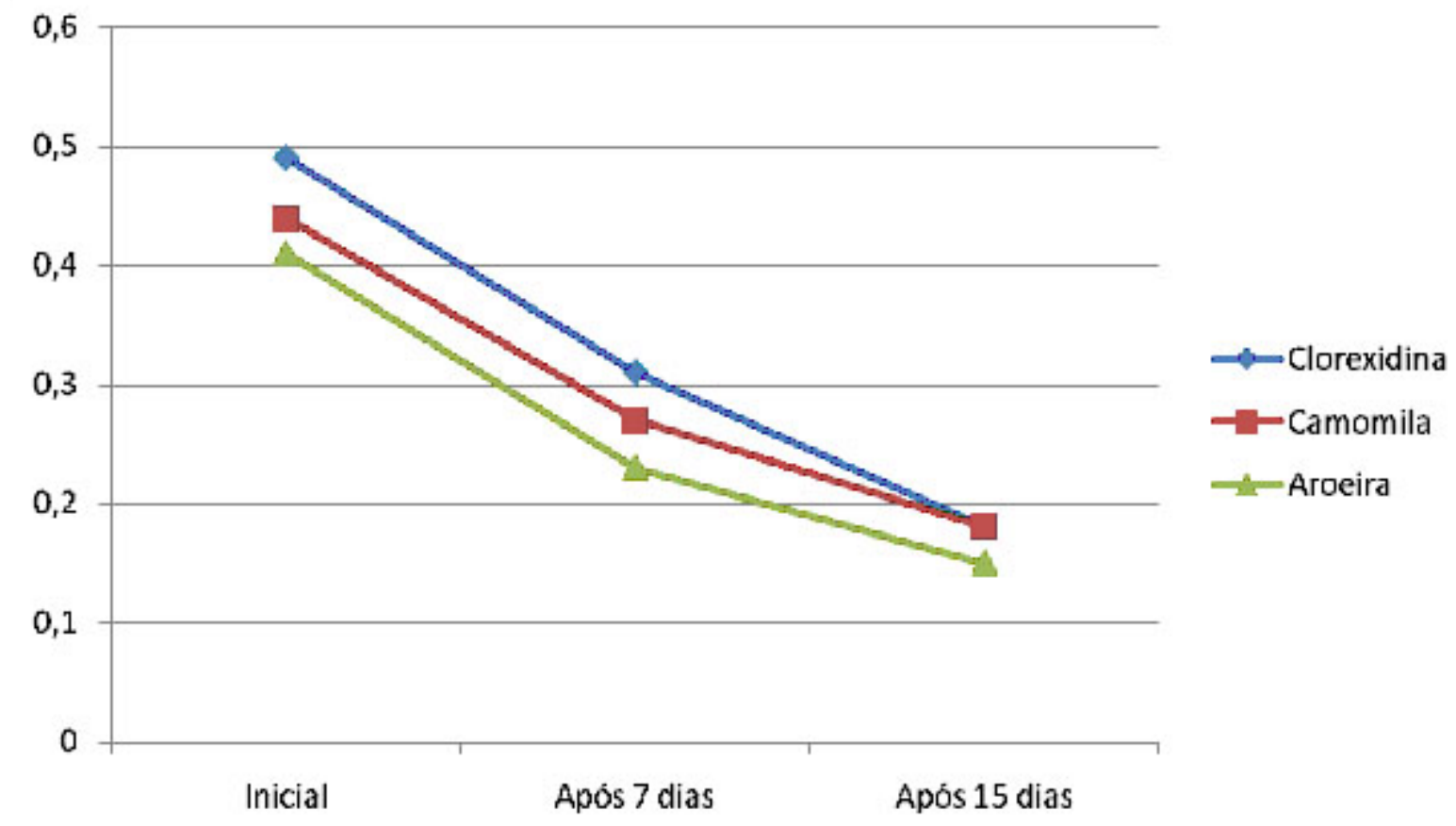

FIGURA 3. Índices de sangramento inicial, após 7 e 15 dias nos grupos Clorexidina, Camomila e Aroeira

diferenças estatisticamente significativas entre os diferentes grupos (Tabela 2 e Figura 2).

Utilizando-se dos mesmos testes estatísticos, foi realizada a avaliação com o índice de sangramento, observando-se uma redução significativa em cada grupo da pesquisa. $\mathrm{Na}$ comparação entre os grupos estudados, constatouse diferenças estatisticamente significativas apenas nos períodos de 7 e 15 dias, apresentando o grupo com bochecho de Aroeira menores índices de sangramento quando comparado ao bochecho com Clorexidina e com Camomila, conforme está discriminado na Tabela 3 e pode ser visualizado na Figura 3.

De acordo com a tabela 4 e a figura 4 , foram observadas reduções significativas dos índices de placa (IP) e de sangramento gengival (ISG) nos três grupos. Entretanto, para estimar qual destes foi mais eficaz, calculou-se a diferença entre o momento final e o inicial de cada grupo, culminando na taxa bruta de redução dos índices. Nos índices de placa, foram observadas diferenças significativas entre os grupos, apresentando o bochecho de camomila a maior redução no IP $(1,03)$ e o de aroeira, a menor redução $(0,70)$. Para o índice de sangramento, os resultados foram equivalentes, de forma que não foram consideradas diferenças significativas do ponto de vista estatístico.

\section{DISCUSSÃO}

Com o desenvolvimento da indústria farmacêutica a maioria da população, principalmente dos centros urbanos, substituiu as plantas in natura pelas drogas industrializadas, que se tornaram mais acessíveis e aceitas pela população. No entanto, nestas duas últimas décadas, tem sido observado um crescente interesse da comunidade científica pela fitoterapia, o que tem levado ao desenvolvimento de várias pesquisas baseadas em práticas populares (Albuquerque \& Hanazaki, 2006).

Os produtos fitoterápicos possuem ação 
TABELA 4. Estatísticas descritivas e inferenciais da redução de placas e sangramentos nos grupos Clorexidina, Camomila e Aroeira

\begin{tabular}{|c|c|c|c|c|}
\hline Redução & Clorexidina & Camomila & Aroeira & KW (p) \\
\hline IP & $0,97 \pm 0,27$ & $1,03 \pm 0,28$ & $0,70 \pm 0,25$ & $12,691(0,002)^{*}$ \\
\hline ISG & $0,30 \pm 0,07$ & $0,25 \pm 0,10$ & $0,26 \pm 0,14$ & $3,519(0,172)$ \\
\hline
\end{tabular}

* Diferença estatisticamente significante ao nível de 5\%.

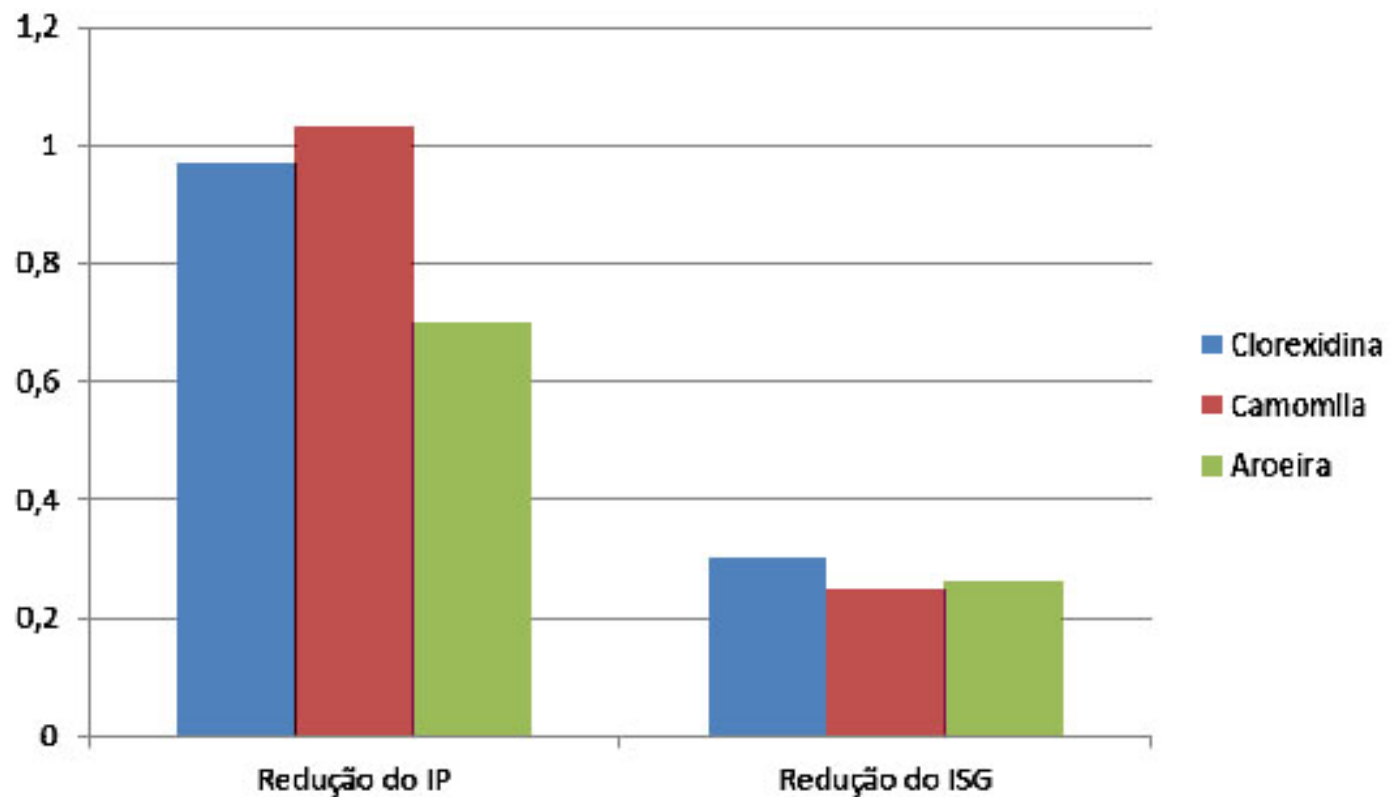

FIGURA 4. Redução de IP e ISG nos grupos Clorexidina, Camomila e Aroeira

mais suave que os medicamentos alopáticos. Isso se deve ao fato de que o princípio ativo da planta não é utilizado de maneira isolada, atuando juntamente com outras substâncias presentes nas plantas. Esse conjunto de elementos é chamado de fitocomplexo e são justamente os fitocomplexos, os responsáveis pelo efeito terapêutico suave e pela redução dos efeitos colaterais (Bara, 2006).

As plantas medicinais constituem um importante recurso terapêutico para o tratamento da saúde. A abrangência da utilização de fitoterápicos é vasta e engloba fins variados, sobretudo em relação à saúde bucal. A eficácia de tais plantas, empregadas em enxaguatórios bucais, tem sido investigada para o tratamento de gengivites, e os resultados sugerem que tais princípios ativos podem ser utilizados como apoio à terapia das doenças periodontais e como profilaxia de rotina (Cordeiro et al., 2006a).

A Fitoterapia faz parte do Sistema Único de Saúde, sendo possível a sua inclusão médica e odontológica (Brasil, 2006). O Brasil possui grande potencial para o desenvolvimento da Fitoterapia aplicada à Odontologia, já que apresenta a maior diversidade vegetal do mundo, ampla sócio- diversidade, uso de plantas medicinais vinculado ao conhecimento tradicional, e a tecnologia para validar cientificamente esse conhecimento, para que esses fitoterápicos sejam usados para afecções específicas, na dosagem correta e em tempo determinado, a fim de se obter o efeito terapêutico desejado (Albuquerque \& Hanazaki, 2006).

De acordo com as citações de Padilha et al. (2006), o controle químico da placa bacteriana auxilia a remoção mecânica, prevenindo a instalação da cárie e das doenças periodontais que estão intimamente relacionadas a sua presença. No entanto, os enxaguatórios em nenhum caso devem substituir os métodos mecânicos de remoção da placa, e sim, atuar como auxiliares do mesmo (Marinho \& Araújo, 2007).

Alves (2005) avaliou a atividade antimicrobiana in vitro da aroeira sobre os microorganismos da cavidade oral, observando que o extrato hidroalcoólico dessa planta apresentava atividade bactericida e bacteriostática sobre $S$. mutans, S. mitis, S. sobrinus, S. sanguis e L. casei, como também ação antifúngica sobre $C$. albicans, C. tropicalis e C. krusei. $O$ referido autor verificou também que a aroeira exibia ação antiaderente in 
vitro semelhante à clorexidina $0,12 \%$, demonstrando a capacidade dessa planta em inibir a síntese do glucano pela glicosiltransferase.. No presente estudo, ficou demonstrado que o extrato de aroeira possui capacidade inferior à clorexidina no controle da placa bacteriana.

Confirmando as propriedades medicinais atribuídas à aroeira, Feitosa, Marques e Melo (2000), compararam a eficácia dos efeitos de bochechos com clorexidina com um extrato bruto da referida planta em 30 (trinta crianças) durante quatro dias, sendo afirmado por tais pesquisadores que o grupo de pacientes que utilizou a aroeira apresentou uma maior redução da placa bacteriana e um significativo aumento do $\mathrm{pH}$ salivar quando comparado aos índices apresentados pelas crianças que utilizaram a clorexidina. Estes resultados não estão de acordo com a atual pesquisa, na qual o bochecho de aroeira mostrou uma redução da placa bacteriana inferior ao bochecho de clorexidina.

Em estudo realizado por Cedro et al. (2004), relatam que a utilização de bochechos contendo clorexidina e aroeira como princípios ativos, reduziram sensivelmente os índices de placa e gengivite em médias percentuais no vigésimo dia da pesquisa, quando comparados aos índices iniciais aferidos no primeiro dia de monitoramento. Concluiu-se ainda que o bochecho com clorexidina obteve resultado superior na redução dos índices de placa e gengivite quando comparado ao desempenho daquele realizado com aroeira. No presente estudo, obtiveram-se resultados diferentes, o bochecho com aroeira se revelou inferior à clorexidina em relação à redução do índice de placa e semelhante quanto à redução da inflamação gengival (gengivite).

Ensaios clínicos, utilizando a camomila (Matricaria recutita L.) como dentrifício, demonstraram uma redução na gengivite em $97 \%$ dos casos relatados (Ryscky, 1991). Em estudo realizado por Lucena et al. (2009), o bochecho de camomila apresentou eficácia comparável com à clorexidina no tratamento da gengivite crônica, estando de acordo com o resultado encontrado na atual pesquisa.

Um maior número de pesquisas na área de fitoterapia no tratamento das doenças periodontais são propostas tendo em vista o crescente interesse tanto da comunidade acadêmica, como por parte do setor público e privado em nosso país.

A utilização destes produtos fitoterápicos, economicamente mais viáveis, mostra-se como uma alternativa interessante, contribuindo para melhorar o acesso da população aos cuidados com a prevenção e tratamento de doenças periodontais (Cordeiro et al. 2006b).

\section{CONCLUSÃO}

Os bochechos à base de extrato de Aroeira e de camomila mostraram-se eficazes no controle da placa bacteriana, bem como no tratamento da gengivite crônica, com resultados similares ao da clorexidina a $0,12 \%$. No entanto, bochecho à base de extrato de Camomila mostrou-se o mais eficaz no controle da placa bacteriana, quando comparado ao bochecho à base de extrato de Aroeira e ao bochecho de clorexidina a $0,12 \%$. As plantas medicinais Aroeira e Camomila apresentaram ações antimicrobianas e antiinflamatórias, podendo assim indicadas como agentes terapêuticos alternativos para o estabelecimento e a manutenção de um tecido gengival sadio.

\section{REFERÊNCIA}

ACHTERRATH-TUCKERMANN, K.R. et al. Pharmakologische Untersuchungen von KamillenInhaltsstoffen. Planta Medica, v. 39, n.1, p. 38-50, 1980. AINAMO, J.; BAY, I. Problems and proposals for recording gingivitis and plaque. Internacional Dental Journal. v.25, n.4, p.229-35, 1975.

ALBUQUERQUE, U.P.; HANAZAKI, N. As pesquisas etnodirigidas na descoberta de novos fármacos de interesse médico e farmacêutico: fragilidades e pespectivas. Revista Brasileira de Farmacognosia v.16 ( suppl.0), p.678-89, 2006.

ALVES, P. M. Atividade antimicrobiana e antiaderente in vitro dos extratos da Myracrodruonurundeuva Al., Malva sylvestris e Psidiumguajava Linn. sobre microorganismos do biofilme dental e cepas do gênero Candida. [Dissertação]. João Pessoa: Faculdade de Odontologia. Universidade Federal da Paraíba, 2005. AMMON, H.P.T.; KAUL, R. Pharmakologie der kamille und ihrerlnhaltstoffe. Deutsche Apotheker Zeitung, v. 132 (Sup.27), p.3-26, 1992.

BARA, M. T. F. et al. Determinação do teor de princípios ativos em matérias-primas vegetais. Revista Brasileira de Farmacognosia, João Pessoa, v. 16, n. 2, p. 211-215, abr./jun. 2006.

BEIKLER, T.; FLEMMIG T. F. Oral biofilm-associated diseases: trends and implications for quality of life, systemic health and expenditures. Periodontology 2000. v.55, n.1, p.87-103, 2011.

BORBA, A.M.; MACEDO, M. Plantas medicinais usadas para a saúde bucal pela comunidade do bairro Santa Cruz, Chapada dos Guimarães, MT, Brasil. Acta Botanica. Brasilica. v.20, n.4, p.771-782, 2006.

BRANDÃO, E.H.S. et al. Antimicrobial activity of coffeebased solutions and their effects on Streptococcus mutans adherence. Brazilian Journal of Oral Science. v.6, n.20, p.1274-7, 2006.

BRAGA P. C. et al. Antioxidant activity of bisabolol: inhibitory effects on chemiluminescence of human neutrophil bursts and cell-free systems. Pharmacology v.83, n. 2, p.110-115, 2009.

BRASIL. Ministério da Saúde. Agência Nacional de Vigilância Sanitária. Portaria $n^{\circ}$ 971, de 3 de maio de 
2006. Diário Oficial da República Federativa do Brasil, Brasília, 2006.

CEDRO, I. R. et al. Estudo comparativo do efeito de bochechos de clorexidina e aroeira Schinus terebinthinfolius na saúde gengival de pacientes com gengivite. Anais da

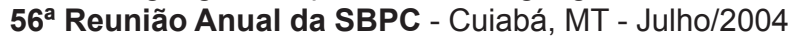
CORDEIRO, C.H.G.; SACRAMENTO, L.V.S.; CORREA, M.A.; PIZOLLITO, A.C.; LARA, E.H.G.; MORAES, H.P. Avaliação farmacognóstica e atividade antibacteriana de extratos vegetais empregados em gel dentifrício. Revista Brasileira de Plantas Medicinais. v.8, n.4, p.173-182, 2006a.

DOMEJEAN-ORLIAGUET S.; GANSKY S. A.; FEATHERSTONE J. D. Caries risk assessment in an educational environment. Journal of Dental Education. v.70, n. 12, p. 1346-1354, 2006.

FEITOSA, M.L.; MARQUES, K.C.V.; MELO, E.J.M.F. Comparação da eficácia de bochecho à base de extrato de aroeira (Schinus terebithifolius) e clorexidina na redução do índice de placa bacteriana. João Pessoa: ed. Universitária-UFPB, n.20, p.40, 2000.

GJERMO, P. et al. Relationship between plaque inhibiting effect and retention of chlorohexidine in the human oral cavity, Archives of Oral Biology, v.19, n.11, p. 10311034, Nov 2000.

GUERRA, M. J. M. et al. Actividad Antimicrobiana de um Extracto Fluido al $80 \%$ de Shinus terebinthifolius raddi (COPAL). Revista Cubana de Plantas Medicinales. v.5, n.1, p.23-5, 2000.

GUTMANN J. L. et al. Identify and define all diagnostic terms for periapicalD periradicular health and disease States. Journal of Endodontics v.35, n.12, p.1658-1674, 2009.

GUNSOLLEY, J.C. A meta-analysis of six-month studies of antiplaque and antigingivitis agents. Journal of the American Dental Association, v. 137, n. 12, p. 16491657. 2006.

JARDIM JÚNIOR, E.G. et al. Eficácia do listerine sobre a placa. Revista Gaúcha Odontológica v. 46, n.1, p.7078, 1998.

JUIZ, P. J. L.;ALVES, R. J. C; BARROS, T. F. Uso de produtos naturais como coadjuvante no tratamento da doença periodontal. Revista Brasileira de Farmacognosia. v.20, n.1,p.134-139, 2010.

LIMA JÚNIOR, J. F.; DIMENSTEIN, M. A Fitoterapia na Saúde Pública em Natal/RN: visão do odontólogo. Revista Saúde v. 8, n.19, p. 37-44, 2006.

LINS, R.D.A.U. et al. Estudo da raspagem manual isolada e associada à irrigação subgengival com clorexidina e aroeira. Perio News. v.4, n. 4.2010.

LOUREIRO, C. C. S. et al. Efeitos adversos dos medicamentos tópicos e sistêmicos na mucosa bucal. Revista Brasileira de Otorrinolaringologia. v.70, n.1, p.106-111, 2004.

LUCENA, R.N. et al. Estudo clínico comparativo do efeito anti-inflamatório da Matricaria recutita e da clorexidina em pacientes com gengivite crônica. Revista Brasileira de Pesquisa em Saúde v.11, n.3, p.31-36, 2006.

MARINHO, B.V.S.; ARAÚJO, A.C.S. Uso dos enxaguatórios bucais sobre a gengivite e biofilme dental. International Journal of Dentistry v. 6, n. 4, p.124-131, 2007.

OLIVEIRA, F.Q.; GOBIRA, B.; GUIMARÃES, C.; BATISTA, J.; BARRETO, M.; SOUZA. M. Espécies vegetais indicadas na odontologia. Revista Brasileira de Farmacognosia v.17, n.3, p.466-476, 2007.

PADILHA, W.W.N. et al. Susceptibilidade in vitro de bactérias bucais a tinturas fitoterápicas. Revista Odonto Ciência v. 21, n. 53, p. 232-237, 2006.

PEREIRA, C.V. Ação de amostras de Streptococcus mutans e Streptococcus sobrinus sobre diferentes carboidratos com ênfase dentária - estudo in vitro. Revista Passo Fundo v.4, n.1, p. 33-39, 1999.

PETTI, S.; HAUSEN, H. Caries-preventive effect of chlorhexidine gel applications among high-risk children. Caries Research. v.40, n.6, p.514-21, 2006.

RYSCKY, S. The effects of officinal herbs on inflammation of gingival margin: a clinical trial with a newly formulated toothpaste. Journal Clinical of Dentistry. v.2, n. 1, p.1921, 1991.

SALGADO, A.D.Y. et al. Antiplaque and antigingivitis effects of a gel containing Punica granatum Linn extract: a double-blind clinical study in humans. Journal Applied Oral Science. v.14, n.3, p.162-6, 2006.

SANTOS, L.C.; AMORIM, M.M.R. Uso da Aroeira (Schinus terebinthifolius raddi) para Tratamento de infecções vaginais. Femina v.30, n.6, p.339-342, 2002.

SILNESS, J.; LÖE, H. Periodontal disease in pregnancy II: correlation between orhygiene and periodontal conditions. Acta Odontologica Scandinavica. v.22, n.1, p.121- 35. 1964.

SRIVASTAVA J. K.; PANDEY M.; GUPTA S. Chamomile, a novel and selective Cox-2 inhibitor with anti-inflammatory activity. Life Science v.85, n.19-20, p.663-669, 2009.

VAN DER WEIJDEN, G.A. et al. Effect of pre-experimental maintenance care duration on the development of gingivitis in a partial mouth experimental gingivitis model. Journal Periodontal Research. v. 29, n.3, p.168-73, 1994.

VILLALOBOS, O.J.; SALAZAR, C.R.; SÁNCHEZ, G.R. Efecto de un enjuague bucal compuesto de aloe vera em la placa bacteriana e inflamación gingival. Acta Odontologica Venezolana. v.39, n.2,p.16-24, 2001. WERKMAN, C.; GRANATO, D.C.; KERBAUY, W.D.; SAMPAIO, F.C.; BRANDÃO, A.A.H.; RODE, S.M. Aplicações terapêuticas da Punica granatum L. (romã). Revista Brasileira de Plantas Medicinais v.10, n.3, p.104-111, 2008.

Rev. Bras. PI. Med., Botucatu, v.15, n.1, p.112-120, 2013. 